\title{
PASSAGEM INFERIOR DE FAUNA E CERCA GUIA COMO FORMA DE MITIGAÇÃO DOS IMPACTOS AMBIENTAIS
}

\section{PASS LOWER FAUNA AND ABOUT HOW TO GUIDE MITIGATION FORM OF ENVIRONMENTAL IMPACTS}

\author{
Cássio Rodinei dos Santos \\ MBA em Infraestrutura de Transportes e Rodovias. UNICID \\ Rafael Vieira da Silva \\ UniABEU
}

\begin{abstract}
RESUMO
O presente estudo busca apresentar a passagem de fauna e cercas guia que são as principais estruturas utilizadas nas rodovias, bem como nas ferrovias, para mitigação dos impactos ambientais sobre a fauna. Impactos que são consequência do efeito barreira, efeito de evitação e atropelamentos. Além dos altos custos gerados pelos acidentes envolvendo motoristas e animais, a fragmentação do território pelos empreendimentos tende a colocar a fauna em uma situação de risco, tanto pela redução da oferta de alimento como pelo baixo polimorfismo que podem provocar a extinção das espécies. Com o desenvolvimento da Ecologia de Estradas e dos processos de licenciamento procura-se minimizar os impactos sobre o meio ambiente. Destaca-se a importância para a conscientização e colaboração da sociedade em geral para a preservação e manutenção das estruturas de proteção a fauna.
\end{abstract}

Palavras-chave: Licenciamento Ambiental, Ecologia de Estradas, Efeito Barreira e Evitação.

\begin{abstract}
This study aims to present the passage of fauna and fences guide are the main structures used in highways and the railways, for mitigation of environmental impacts on wildlife. Impacts that are a result of the barrier effect of avoidance and run over effect. Besides the high costs caused by accidents involving drivers and animals, fragmentation of the territory by enterprises tends to put wildlife in an unsafe situation, both by reducing the food supply and the low polymorphism that may cause the extinction of species. With the development of Road Ecology and licensing procedures seek to minimize impacts on the environment. It highlights the importance for the awareness and cooperation of society in general for the preservation and maintenance of wildlife protection structures.
\end{abstract}

Keywords: Environmental Licensing, Road Ecology, Barrier effect and Avoidance. 


\section{INTRODUÇÃO}

O setor rodoviário representa um importante meio de ligação entre os mais diversos setores da economia. As rodovias são o meio físico por onde uma fonte indutora de riquezas e de produção se desenvolve pela geração de oportunidades de emprego, redução de distâncias e distribuição de renda.

Para que a sociedade consiga a melhoria de sua qualidade de vida, a infraestrutura de transportes deve se desenvolver. Atualmente a competitividade da economia brasileira passa por dificuldades, e muito disso tem a ver com o insuficiente investimento em infraestrutura de transportes. Observa-se que os bens produzidos no país podem ser mais competitivos na fase de produção, mas perdem competitividade, notadamente, no quesito infraestrutura de transportes, devido a uma matriz modal deficiente, onde as estradas (principal meio de escoamento da produção nacional) encontra-se em estado tal que não são capazes de atender as necessidades de transporte de carga nacionais. Além disso, as mas condições de conservação das rodovias brasileiras acarretam em um crescente número de acidentes, desperdícios de carga e gasto elevado com manutenção e combustíveis (BERNUCCl, et al, 2006).

Aliada as condições econômicas de desenvolvimento, as obras viárias devem proporcionar aos seus usuários, segurança, conforto, economia e ainda, soluções para neutralizar ou atenuar os danos gerados sobre a biodiversidade. Esta última demanda vem sendo observada na última década devido o desenvolvimento da Ecologia de Estradas, que representa os impactos biológicos, sociais e econômicos ligado ao tema. Por se tratar de um campo relativamente novo do conhecimento, existem limitadas certezas e comprovações científicas, considerando ainda que a combinação de fatores bióticos e físicos de cada projeto é única. Cada caso deverá ser analisado individualmente e a melhor alternativa para mitigar os impactos gerados pelos empreendimentos rodoviários (novos e existentes), poderá ser escolhida. Considerando que é de interesse da sociedade em geral, que os recursos públicos sejam aplicados com parcimônia, e resultem na melhoria da qualidade de vida das pessoas, sem que para isso se comprometam os processos 
ecológicos e nem onerem as contas públicas pela escolha de alternativas que minimizem ao extremo o impacto das rodovias sobre a fauna (LAUXEN, 2012).

No Brasil a inserção de medidas para a proteção da fauna silvestre contra atropelamentos é recente. Neste contexto, procura-se inicialmente realizar um diagnóstico da fauna existente a fim de identificar as espécies e as áreas que mais demandam por medidas mitigadoras aos acidentes envolvendo animais e motoristas. Pois, não há solução única que possa ser generalizada para todas as situações, considerando que cada rodovia possui um conjunto diferente de condições ambientais e de aspectos de engenharia. As medidas de proteção à fauna nas imediações de rodovias são um conjunto amplo que envolve a implantação de dispositivos, iniciativas educativas e de fiscalização dos usuários. Dentre as soluções mais utilizadas de dispositivos, podem-se citar as cercas para evitar a travessia de animais sobre as rodovias, induzindo sua travessia por passagens de fauna inferiores. As quais, conforme a necessidade pode ser associada a outras estruturas como sinalização rodoviária preventiva e de advertência e ainda a dispositivos de controle de velocidade (BRASIL, 2012).

Os métodos ou estruturas de mitigação que permitem uma avaliação objetiva de resultados são as passagens de fauna (nas suas mais diversas modalidades), onde o número de indivíduos e espécies que as utilizam pode ser quantificado, e as cercas que representam as melhores avaliações quanto à potencialidade para reduzir os efeitos diretos e mais visíveis das rodovias. Lembrando sempre que a eficiência de cada um é dependente das características biológicas e ecológicas das espécies, específicos de uma dada área (LAUXEN, 2012).

$O$ processo de licenciamento ambiental oferece uma excelente oportunidade tanto para a discussão de ideias, conceitos e propostas, quanto para a geração de conhecimento, em particular se conduzido no aspecto técnico sob critérios cientificamente válidos (LAUXEN, 2012). Assim, este trabalho objetiva apresentar informações sintetizadas a respeito das passagens de fauna e cerca guia, além dos processos de licenciamento ambiental envolvido e dos programas de divulgação. Observa-se também a necessidade de conscientização da sociedade em geral para a conservação e manutenção das estruturas de preservação da fauna. 


\section{LICENCIAMENTO AMBIENTAL}

O licenciamento ambiental, segundo a Resolução CONAMA oo 237/1997, é definido como o "procedimento administrativo pelo qual o órgão ambiental competente licencia a localização, instalação, ampliação e a operação de empreendimentos e atividades utilizadora de recursos ambientais, consideradas efetiva ou potencialmente poluidoras ou daquelas que, sob qualquer forma, possam causar degradação ambiental". Neste contexto estão todas as obras de infraestrutura, bem como as rodovias (RESOLUÇÃO CONAMA № 237, 1997).

Em conformidade com o estabelecido pela Constituição da República Federativa do Brasil, onde define que "Todos tem direito a um meio ambiente ecologicamente equilibrado, bem de uso comum do povo e essencial à sadia qualidade de vida, impondo-se ao Poder Público e à coletividade o dever de defendê-lo e preservá-lo para as presentes e futuras gerações" (BRASIL, 1988b). Na sua implantação são exigidas ações multidisciplinares, com responsabilidades compartilhadas e com o apoio e a participação da sociedade, no intuito de impedir ou de atenuar os impactos ambientais com efeitos deletérios. O licenciamento ambiental se caracteriza por uma obrigação legal prévia à instalação de qualquer obra potencialmente poluidora ou degradadora do meio ambiente, tendo com importante característica a participação da sociedade na tomada de decisões por meio de Audiências Públicas (PIMENTA, et al, 2014).

O desenvolvimento de instrumentos de Avaliação de Impacto Ambiental (AIA) serve de subsídio para adequar às exigências ambientais aos processos de licenciamento, planejamento, projeto, construção e operação dos empreendimentos. Pela AIA as propostas de medidas mitigadoras são delineadas, os programas e demais condições necessárias para reduzir os possíveis danos ambientais advindo de uma obra, definidos. Esse processo envolve a Avaliação Ambiental Estratégica (AAE) e Avaliação Ambiental Integrada (AAI), que permitem a previsão de prováveis impactos ambientais, bem como a suas características, e a partir disso, sirva de embasamento para que um órgão ambiental competente defina o tipo de estudo ambiental ou 
documento técnico que deve ser desenvolvido pelo empreendedor para enfim obter as licenças ambientais.

Dentre os estudos ambientais ou documentos técnicos pode-se citar: Estudo de Impacto Ambiental (EIA) e Relatório de Impacto Ambiental (RIMA), Plano Básico Ambiental (PBA), Plano de Controle Ambiental (PCA), Relatório de Controle Ambiental (RCA), e quando necessário o Plano de Recuperação Ambiental de Áreas Degradadas (PRAD). A Resolução CONAMA oㅡ 237/1997 (CONAMA, 1997a) estabelece os tipos de licenças que o Poder Público deve expedir conforme o tipo, a natureza, características e fase do empreendimento ou atividade (PIMENTA, et al, 2014).

A licença prévia (LP) é concedida na fase dos estudos iniciais para a obra, precedendo inclusive o projeto básico, deve ser providenciada pelo órgão público contratante e deve ser existente ao tempo da licitação pública, atestando a viabilidade ambiental do novo empreendimento.

A licença de instalação (LI) é requerida pelo empreendedor vencedor do processo licitatório, com objetivo de receber autorização para dar início à execução dos serviços.

A licença de operação (LO) é providenciada após a conclusão dos serviços e autoriza o contratante a iniciar a utilização do empreendimento. Ela somente é concedida após a constatação da execução de todas as condicionantes estabelecidas nas licenças anteriores (LP e LI) e, pode também impor novas condicionantes a utilização do empreendimento (PESSOA JúNIOR, 2014).

Referente às rodovias federais, cujo Licenciamento Ambiental Federal (LAF) é conduzido pelo IBAMA, existem três procedimentos distintos e dependentes da tipologia do empreendimento a ser licenciado a saber: Licenciamento Ambiental Federal Ordinário, Licenciamento Ambiental Federal Específico e Licenciamento Ambiental Federal para fins de regularização ambiental de rodovias federais pavimentadas em operação que não possuem licença ambiental. A figura 1 apresenta um resumo dos tipos de licenciamento ambiental de rodovias federais conforme a IN 184/2008 (IBAMA, 2008) e da Portaria MMA no 289/2013 (BRASIL, 2013b).

Figura 1: Licenciamento Ambiental de Rodovias Federais (PIMENTA, et al, 2014). 


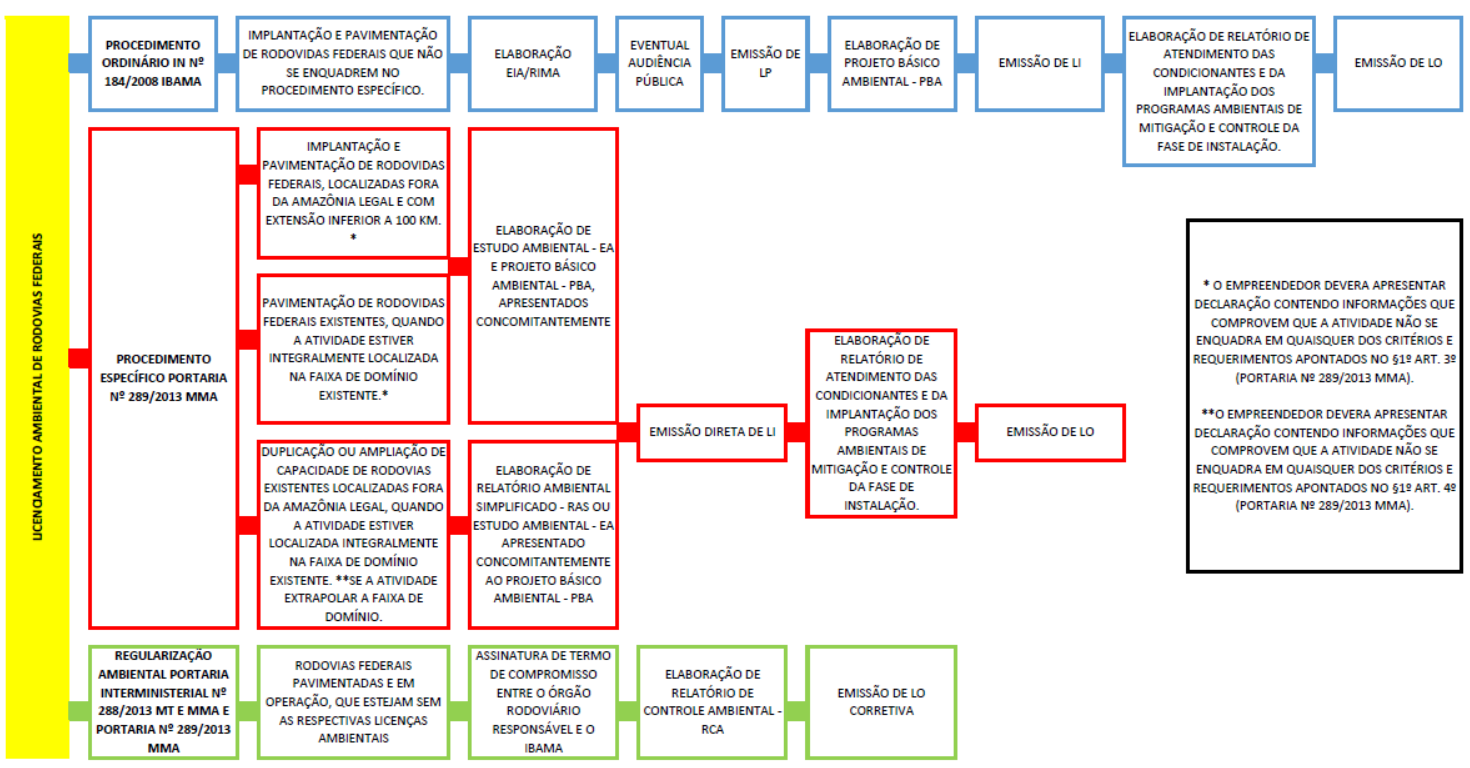

Para o licenciamento ambiental de obras rodoviárias federais existe uma série de normativas legais a serem consultadas e seguidas. Na tabela 1 estão apresentadas essas normas.

Tabela 1 - Normas federais para licenciamento ambiental (LAUXEN, 2012).

\begin{tabular}{|c|c|c|}
\hline Referência & Data & Assunto \\
\hline Lei Federal n 6.938/81 & $31 / 08 / 1981$ & $\begin{array}{l}\text { Dispões sobre a Política Nacional do Meio } \\
\text { Ambiente. }\end{array}$ \\
\hline $\begin{array}{l}\text { Resolução CONAMA nº } \\
001 / 86\end{array}$ & 23/01/1986 & $\begin{array}{l}\text { Dispões sobre critérios básicos e diretrizes gerais } \\
\text { para a avaliação de impacto ambiental. }\end{array}$ \\
\hline $\begin{array}{l}\text { Resolução CONAMA nº } \\
006 / 86\end{array}$ & 24/01/1986 & $\begin{array}{l}\text { Dispões sobre a aprovação de modelos para } \\
\text { publicação de pedidos de licenciamento. }\end{array}$ \\
\hline $\begin{array}{l}\text { Resolução CONAMA nº } \\
009 / 87\end{array}$ & 03/12/1987 & $\begin{array}{l}\text { Dispões sobre a realização de Audiências } \\
\text { Públicas no processo de licenciamento. }\end{array}$ \\
\hline Constituição Federal & $05 / 10 / 1988$ & Capítulo VI: Do Meio Ambiente. \\
\hline $\begin{array}{l}\text { Decreto Federal } \\
99.274 / 90\end{array}$ & 06/06/1990 & $\begin{array}{l}\text { Regulamenta a Lei Federal } n^{\circ} 6.938 / 81 \text {, que } \\
\text { dispõe sobre a Política Nacional do Meio } \\
\text { Ambiente. }\end{array}$ \\
\hline $\begin{array}{l}\text { Resolução CONAMA no } \\
237 / 97\end{array}$ & 22/12/1997 & $\begin{array}{l}\text { Dispões sobre a revisão e complementação dos } \\
\text { procedimentos e critérios utilizados para o } \\
\text { licenciamento. }\end{array}$ \\
\hline Lei Federal no 9.985/00 & $18 / 07 / 2000$ & $\begin{array}{l}\text { Institui o Sistema Nacional de Unidades de } \\
\text { Conservação da Natureza (SNUC) e prevê a } \\
\text { compensação ambiental. }\end{array}$ \\
\hline $\begin{array}{l}\text { Resolução CONAMA no } \\
281 / 01\end{array}$ & $12 / 07 / 2001$ & $\begin{array}{l}\text { Dispões sobre modelos de publicação de pedidos } \\
\text { de licenciamento. }\end{array}$ \\
\hline $\begin{array}{l}\text { Resolução CONAMA no } \\
303 / 02\end{array}$ & 20/03/2002 & $\begin{array}{l}\text { Dispõe sobre parâmetros, definições e limites de } \\
\text { Áreas de Preservação Permanente. }\end{array}$ \\
\hline Decreto Federal 4.340/02 & 22/08/2002 & $\begin{array}{l}\text { Regulamente artigos da Lei do SNUC e } \\
\text { compensação ambiental. }\end{array}$ \\
\hline $\begin{array}{l}\text { Instrução Normativa } \\
\text { IBAMA nº } 183 / 08\end{array}$ & $17 / 07 / 2008$ & $\begin{array}{l}\text { Cria o Sistema Informatizado do Licenciamento } \\
\text { Ambiental - SisLic, no âmbito do IBAMA. }\end{array}$ \\
\hline $\begin{array}{l}\text { Instrução Normativa } \\
\text { IBAMA no } 184 / 08\end{array}$ & $17 / 07 / 2008$ & $\begin{array}{l}\text { Estabelece os procedimentos para o } \\
\text { licenciamento ambiental federal. }\end{array}$ \\
\hline Decreto Federal 6.848/09 & $14 / 05 / 2009$ & $\begin{array}{l}\text { Altera e acrescenta dispositivos ao Decreto } \\
\text { Federal } n=4.340 / 02 \text {, para regulamentar a }\end{array}$ \\
\hline
\end{tabular}




\begin{tabular}{|c|c|c|}
\hline Referência & Data & Assunto \\
\hline & & compensação ambiental. \\
\hline $\begin{array}{l}\text { Resolução CONAMA no } \\
428 / 10\end{array}$ & $17 / 12 / 2010$ & $\begin{array}{l}\text { Dispõe sobre a autorização do órgão responsável } \\
\text { pela administração da Unidade de Conservação } \\
\text { (UC) no âmbito dos processos de licenciamento. }\end{array}$ \\
\hline $\begin{array}{l}\text { Instrução Normativa } \\
\text { IBAMA no 8/11 }\end{array}$ & $14 / 07 / 2011$ & $\begin{array}{l}\text { Regulamenta, no âmbito do IBAMA, o } \\
\text { procedimento da compensação ambiental. }\end{array}$ \\
\hline $\begin{array}{l}\text { Portaria Interministerial } \\
\text { no } 419 / 11\end{array}$ & $26 / 10 / 2011$ & $\begin{array}{l}\text { Regulamenta a atuação dos órgãos e entidades } \\
\text { da Administração Pública Federal envolvidos no } \\
\text { licenciamento. }\end{array}$ \\
\hline Portaria MMA no 420/11 & $26 / 10 / 2011$ & $\begin{array}{l}\text { Dispões sobre procedimentos a serem aplicados } \\
\text { pelo IBAMA na regularização e no licenciamento } \\
\text { ambiental das rodovias federais. }\end{array}$ \\
\hline $\begin{array}{l}\text { Portaria Interministerial } \\
\text { no } 423 / 11\end{array}$ & $26 / 10 / 2011$ & $\begin{array}{l}\text { Institui o Programa de Rodovias Federais } \\
\text { Ambientalmente Sustentáveis para a } \\
\text { regularização ambiental das rodovias federais. }\end{array}$ \\
\hline $\begin{array}{l}\text { Lei Complementar } n^{\circ} \\
140 / 11\end{array}$ & $08 / 12 / 2011$ & $\begin{array}{l}\text { Fixa normas para competência do licenciamento } \\
\text { ambiental, entre outras providências. }\end{array}$ \\
\hline
\end{tabular}

\section{IMPACTOS ECOLÓGICOS DAS ESTRADAS}

A avaliação da viabilidade ambiental de uma obra ou atividade é baseada na previsão de seus impactos e análise da sua importância socioeconômica. Ao definir a viabilidade, o órgão ambiental estabelece como serão neutralizado ou minimizado os impactos negativos e compensados os danos inevitáveis. $\mathrm{Na}$ figura 2, representa as alternativas existentes no contexto de licenciamento ambiental, quando verificada a viabilidade ambiental de uma obra (LAUXEN, 2012).

Figura 2: a) fragmentação do hábitat - impacto; b) alteração do traçado - neutralização do impacto; c) implantação de estruturas de passagem de fauna - mitigação do impacto; d) seleção de hábitat equivalente - compensação (LAUXEN, 2012).

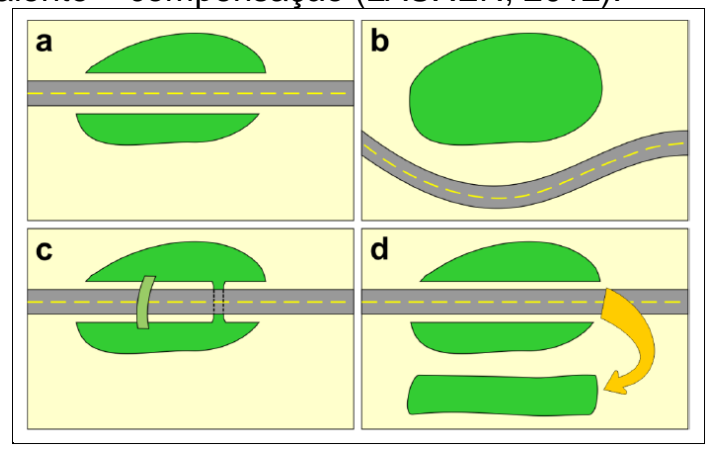

As obras viárias, bem como as ferroviárias, possuem uma característica em comum por se tratarem de obras lineares e importantes fontes de impacto antrópico à conservação da biodiversidade. Estes impactos referem-se a: supressão da vegetação nativa existente na faixa de domínio, a fragmentação 
de hábitats, a criação de barreira física que impede ou dificulta a passagem da fauna de um lado ao outro do empreendimento, o estabelecimento de novas bordas nos remanescentes florestais cortados pela obra e o provável atropelamento de animais (VALEC, 2001).

Os principais tipos de impactos gerados sobre vertebrados terrestres em empreendimentos lineares são: o efeito barreira, o efeito de evitação e atropelamentos (ROMANINI, 2000).

O efeito barreira é uma das principais causas de fragmentação de habitats, pois representa um limitador na movimentação dos vertebrados (GOOSEM, 1997; LYREN, 2001). Seus efeitos são significativos em áreas florestais onde a fragmentação afeta negativamente o tamanho das populações de algumas espécies, aumentando a probabilidade de extinção local além da perda direta de habitat resultante da ocupação. Para barreiras que persiste por muitas gerações, a genética da fauna pode ser alterada, além da formação de meta populações devido ao isolamento. As populações isoladas tendem apresentar baixa heterozigose, o que acarreta o baixo polimorfismo que é a garantia de resistência a mudanças ambientais nas populações evitando ou reduzindo a ação de eventos de extinção (FORMAN \& ALEXANDER, 1998; GOLSDTEIN, et al, 2000).

O efeito de evitação é intensificado devido aos fortes ruídos, vibrações e deslocamentos de ar que são agravados conforme o volume de tráfego e da velocidade média de deslocamentos. Várias espécies de mamíferos apresentam densidades de população muito baixa em áreas distando de $100 \mathrm{a}$ 200 metros de ferrovias, por exemplo. (VALEC, 2001).

Já os atropelamentos representam a perda dos indivíduos da fauna, impacto grave quando atinge espécies ameaçadas de extinção e que existem em baixa densidade populacional (SCHONEWALDCOX \& BUECHNER, 1992; PRADA, 2004), e para as espécies que possuem áreas de vida relativamente grandes e com baixas taxas reprodutivas, como os carnívoros (PRADA, 2004).

A figura 3 representa esquematicamente os impactos ecológicos das estradas que resultam na fragmentação dos habitats, mortalidade de indivíduos e efeito barreira. 
Figura 3: Impactos ecológicos das estradas (LAUXEN, 2012).

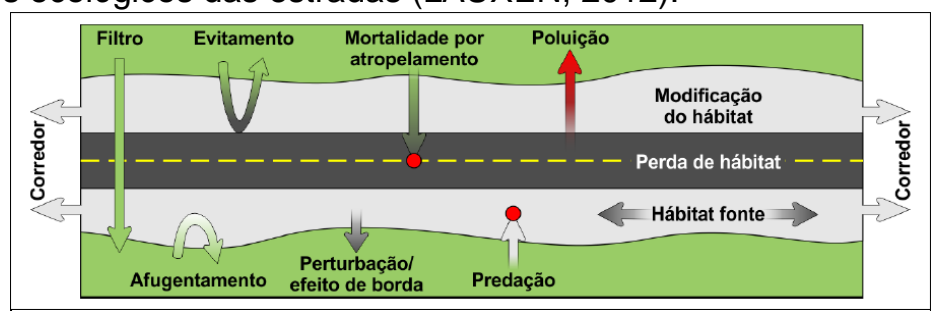

Com o passar do tempo e o desenvolvimento do conceito de ecologia de estradas, várias medidas mitigatórias dos impactos ambientais sobre a fauna foram desenvolvidos e aplicados nas rodovias brasileiras. No entanto, existem poucos dados que comprovam a eficácia das soluções aplicadas.

IUELL (2003) criou um agrupamento das medidas mitigadoras em dois grandes grupos conforme a ênfase no restabelecimento de conectividade ou redução de atropelamentos. No primeiro grupo estão relacionadas às medidas associadas às passagens de fauna e no segundo grupo as medidas referentes ao manejo da fauna, como por exemplo, os cercamentos, e comportamento dos motoristas.

$\mathrm{Na}$ tabela 2 estão relacionadas às medidas conhecidas conforme sua efetividade na minimização dos impactos diretos das rodovias sobre os diferentes grupos de fauna.

Tabela 2 - Medidas mitigadoras dos impactos ambientais sobre a fauna (LAUXEN, 2012).

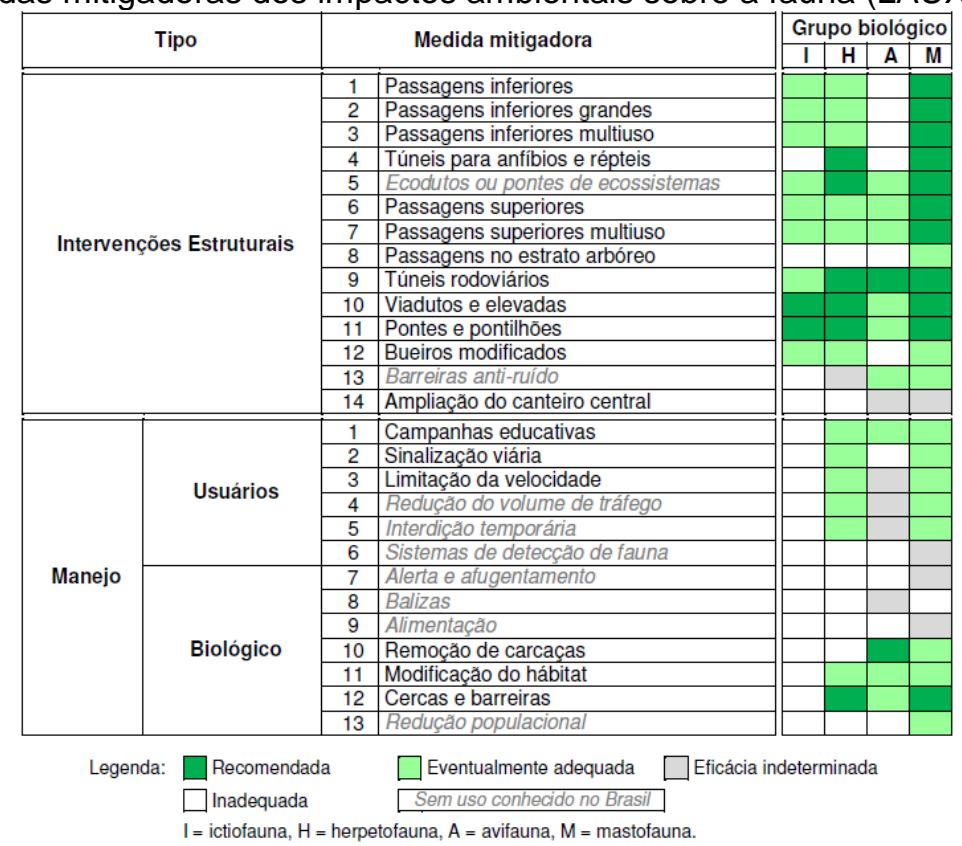

Neste trabalho a ênfase as passagens de fauna inferiores e as cercas guia, que são as mais utilizadas no contexto das obras rodoviárias brasileiras. 


\section{PASSAGEM DE FAUNA E CERCAS GUIA}

Os programas ambientais são de fundamental importância para a implantação de medidas cabíveis em relação aos impactos ambientais, objetivando mitigar, monitorar, controlar, compensar ou restaurar os danos ambientais que ocorrerão em função do empreendimento ou, ainda, potencializar os benefícios dos impactos positivos. $\mathrm{Na}$ tabela 2 são apresentados alguns programas condicionantes para emissão e renovação de licenças ambientais e as principais ações do Plano Ambiental da Construção (PAC). As ações destes programas variam conforme o tipo de empreendimento e os condicionantes presentes na licença de instalação dos mesmos (PIMENTA, et al, 2014).

Tabela 2 - Programas e planos ambientais de obras rodoviárias.

\begin{tabular}{|c|c|c|}
\hline & 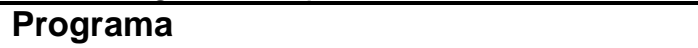 & Ações \\
\hline 1 & $\begin{array}{c}\text { Plano de Gestão e Supervisão } \\
\text { Ambiental }\end{array}$ & \\
\hline 2 & Plano Ambiental da Construção (PAC) & \\
\hline 2.1 & & $\begin{array}{l}\text { Controle de ruídos, gases e material } \\
\text { particulado }\end{array}$ \\
\hline 2.2 & & Sinalização da estrada, desvios e acessos \\
\hline 2.3 & & $\begin{array}{l}\text { Gerenciamento de resíduos sólidos e } \\
\text { efluentes líquidos }\end{array}$ \\
\hline 2.4 & & Controle de processos erosivos \\
\hline 2.5 & & Prevenção de acidentes em fase de obras \\
\hline 2.6 & & $\begin{array}{l}\text { Fiscalização do transporte e } \\
\text { armazenagem de produtos perigosos na } \\
\text { fase de obras }\end{array}$ \\
\hline 2.7 & & Utilização de mão de obra local \\
\hline 2.8 & & $\begin{array}{l}\text { Controle da saúde e segurança do } \\
\text { trabalhador }\end{array}$ \\
\hline 3 & $\begin{array}{c}\text { Programa de Recuperação de Áreas } \\
\text { Degradadas (PRAD) }\end{array}$ & \\
\hline 4 & Programa de Educação Ambiental (PEA) & \\
\hline 5 & Programa de Comunicação Social (PCS) & \\
\hline 6 & Programa de proteção à fauna & \\
\hline 7 & Programa de proteção à flora & \\
\hline 8 & $\begin{array}{c}\text { Programa de proteção e monitoramento } \\
\text { da qualidade das águas }\end{array}$ & \\
\hline 9 & $\begin{array}{c}\text { Programa de prospecção, resgaste do } \\
\text { patrimônio arqueológico e educação } \\
\text { patrimonial }\end{array}$ & \\
\hline 10 & $\begin{array}{c}\text { Programa de gerenciamento de riscos } \\
\text { ambientais }\end{array}$ & \\
\hline 11 & Plano de ação de emergência & \\
\hline 12 & $\begin{array}{l}\text { Programa de desapropriação, } \\
\text { indenização e reassentamento }\end{array}$ & \\
\hline
\end{tabular}




\begin{tabular}{|c|c|}
\hline & rograma \\
\hline 13 & $\begin{array}{c}\text { Programa de apoio às comunidades } \\
\text { indígenas }\end{array}$ \\
\hline 14 & Plano de compensação ambiental \\
\hline
\end{tabular}

Dentro do programa de proteção à fauna estão às cercas e as passagens inferiores e superiores que são medidas mitigatórias empregadas para permitir a conexão entre remanescentes florestais que foram desintegrados pela construção de algum empreendimento, por exemplo, as rodovias, garantindo a dispersão das espécies da fauna local. A fragmentação ou desintegração de remanescentes florestais pode prejudicar a dispersão e o deslocamento da fauna e, desta forma, provocar o isolamento das espécies nas novas unidades florestais, pois, nem todas as espécies são capazes de transpor um obstáculo, como as rodovias, que representam uma barreira física a esses animais.

Além da quantidade insuficiente de alimento presentes nos novos fragmentos e necessário para a sobrevivência das espécies, a falta de parceiros sexuais pode gerar um elevado índice de endogamia. A reprodução entre espécies que apresentam alto grau de parentesco reduz à variabilidade genética da população, tornando-a vulnerável a extinção devido a fatores adversos como as doenças. Por isso, ha necessidade de garantir à fauna a possibilidade de transpor as barreiras de forma segura para que garanta os recursos necessários à sobrevivência, evitando a sua extinção. Neste sentido que as passagens de fauna e cercas surgem como importante recurso para preservação da fauna.

As cercas são uma alternativa para evitar ou guiar a travessia de animais que são capazes de transpor as rodovias e outros empreendimentos lineares. Desta forma o risco de acidentes e colisões pela travessia de animais sobre as rodovias é minimizado e a segurança para os usuários e animais fica preservada.

A escolha dos locais para implantação das intervenções estruturais mitigadoras de impactos ambientais sobre a fauna deve ser realizada por uma equipe especializada. Equipes de biólogos possuem atribuição para averiguar e determinar os pontos críticos que requerem a construção dessas passagens, através do monitoramento contínuo e avaliação da paisagem acerca da rodovia. Identificam os pontos com maiores incidências de travessia de animais 
e de maiores índices de atropelamento, identificando e quantificando as espécies que são prejudicadas pela presença de rodovias e identificando locais cujas características ambientais sejam favoráveis para a construção das passagens e para a dispersão dos animais.

As passagens de fauna construídas sem estudo prévio podem resultar no fracasso ou desperdício de recurso público, pois, serão construções de passagens de fauna mortas, ou seja, sem uso pelos animais.

Em função das várias espécies de animais, como por exemplo: anfíbios, mamíferos, répteis, crustáceos e peixes, a tipologia das passagens de fauna é variada. As passagens subterrâneas localizadas abaixo das rodovias e estradas e as cercas-guia que direcionam esses animais até as passagens, induzem o uso e evitam a travessia sobre as rodovias. Tais passagens podem ser secas ou úmidas. As passagens úmidas aproveitam o escoamento de drenagem da água em seu interior e o leito de córregos, favorecendo a passagem de animais dentro do seu habitat. (GRUPO ECO, 2015).

Uma das soluções para passagem inferior de fauna, que merece destaque, é o emprego de tubos metálicos corrugados tanto para passagens secas como úmidas. Este tipo de sistema de construção não destrutiva permite que a obra seja realizada sem interferência no transito. Solução ideal para obras em rodovias existentes, em operação. A construção de bueiros metálicos corrugados proporciona maior segurança em fase de obra tanto para os condutores quanto para os construtores. Além da segurança atenta-se para a questão financeira, pois a execução de obra de arte corrente convencional em aterros já construídos implica uma série de serviços, além da construção do corpo do bueiro, como: a sinalização diurna e noturna de desvio do tráfego, escavação da pista existente, construção do corpo do bueiro, reaterro e compactação, reconstrução do restante do aterro compactado a $100 \%$, pavimentação conforme o projeto (geralmente composto por macadame seco, base de brita graduada, imprimação, pintura de ligação, execução do concreto asfáltico) e a sinalização definitiva. Conforme a localização, as características de altitude do aterro existente e ainda a estrutura do pavimento a ser recomposta, o uso do bueiro metálico corrugado pode gerar uma economia superior a $80 \%$ se comparada ao custo da execução do bueiro convencional de concreto. Esta análise é fundamentada e validada ao se comparar a execução 
de sistemas convencionais (bueiros tubulares de concreto e galerias) e os bueiros metálicos.

Outro fator importante do uso dos bueiros metálicos é a redução dos impactos ambientais devido à supressão vegetal. A área necessária para a implantação da obra é limitada apenas ao emboque da tubulação no aterro e a previsão de local para depósito do material escavado até a destinação final (áreas de bota-fora). Desta forma, além da preservação ambiental do talude, que não será necessário reconstituir, se reduz ainda os custos de replantio de leivas no talude e a incidência de erosões. As erosões podem acarretar no assoreamento de rios, valas de drenagem e obras de arte corrente, agravando os danos ambientais e encarecendo as medidas mitigatórias.

$\mathrm{Na}$ figura 4 apresentam-se dois exemplos da aplicação dos bueiros metálicos em obras com passagem seca e úmida de fauna.

Figura 4: Aplicação de bueiros metálicos para passagem de fauna (LAUXEN, 2012).

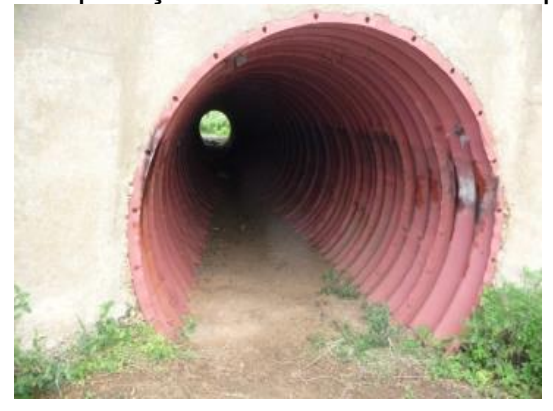

Foto 1: Passagem de fauna seca com emprego de bueiros metálicos corrugados (BR 471/RS - Estação Ecológica do Taim).

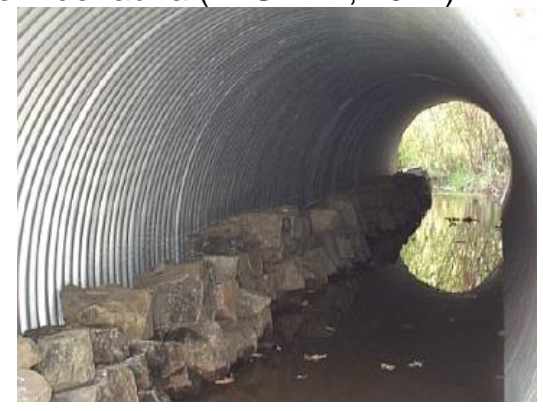

Foto 2: Detalhe da passagem feita com pedras no interior do bueiro metálico corrugado, também utilizado para drenagem - úmido (CALTRANS, 2009).

De qualquer forma, as passagens de fauna e cercas guia são estruturas capazes de proporcionar os seguintes benefícios (GRUPO ECO, 2015):

$\checkmark$ Garantir a conectividade do habitat, favorecendo a dispersão de diferentes espécies;

$\checkmark$ Reduzir em curto prazo a mortalidade de animais, e em longo prazo, evitar que tais espécies sejam extintas;

$\checkmark$ Garantir a manutenção de florestas e outras formações vegetais que dependem dos próprios animais para sua sobrevivência através da polinização e da dispersão de sementes e frutos.

$\checkmark$ Garantir a segurança e a vida dos usuários das vias lineares que podem trafegar com segurança pela rodovia; 
$\checkmark$ Reduzir o ônus das irreparáveis percas e danos de vitimas de acidentes causados por atropelamento de animais;

$\checkmark$ Tornar evidente e fazer a sua parte com relação à responsabilidade ambiental, buscando um desenvolvimento sustentável que procure a sobrevivência da biodiversidade e da população pelas diversas vias do país.

\section{PROGRAMA DE DIVULGAÇÃO E CONSERVAÇÃO}

O Programa de Comunicação Social possui o objetivo de informar aos diversos segmentos sociais intervenientes ou afetados, as características, os impactos, as ações e programas ambientais que serão implantados e a importância do empreendimento para a sociedade. O diálogo deve ser mantido para que as ações previstas sejam viabilizadas, respeitando a qualidade de vida e garantindo a divulgação das informações ao público-alvo de forma organizada. A organização se dá através da definição dos meios de comunicação, conteúdos e expectativa de como essas informações serão aceitas pela comunidade.

O processo de comunicação deve envolver toda população inserida na área de influência direta do empreendimento e em todas as fases do projeto. As principais ações estão na divulgação de folders, reuniões comunitárias, visitas e releases junto às mídias locais, criação de materiais de apoio e acompanhamento e registro das ações dos demais Programas e ainda, a preparação e execução de Campanha de Conscientização Ambiental (PIMENTA, et al, 2014).

Campanhas educativas vêm ocorrendo com a finalidade de divulgar aos motoristas informações como o número de acidentes envolvendo animais, os trechos e horários com maior probabilidade e os cuidados necessários ao avistar animais sobre ou próximo à pista (LAUXEN, 2012). No entanto, a presença de dispositivos, sinalização viária, limitadores de velocidade e campanhas educativas são apenas algumas medidas que permitem a eficácia na proteção à fauna contra atropelamento nas rodovias, e não garante sozinha o seu sucesso. Por isso, a conscientização dos usuários bem como da 
sociedade lindeira aos empreendimentos é de suma importância para a mitigação dos impactos ambientais sobre a fauna.

Os usuários das rodovias devem melhorar o seu comportamento a favor de uma direção preventiva em relação à fauna, e a comunidade lindeira deve colaborar tanto para a conservação das cercas que direcionam os animais silvestres as passagens como para a manutenção das cercas que separam as propriedades da faixa de domínio das rodovias, evitando assim a circulação de animais domésticos junto à pista e os riscos decorrentes (PIMENTA, et al, 2014). Só a conscientização é capaz de produzir um sentimento de conservação e preservação das estruturas, e essa somente será atingida através de campanhas educativas. Desta forma procura-se evitar que acontecimentos semelhantes aos apresentados na sequência de fotos apresentadas na figura 5, aconteçam, nestes casos, ocorre o desperdício de recursos públicos devido à redução da vida útil da estrutura e a necessidade de retrabalho decorrente das reformas.

Figura 5: Descuido com a estrutura de proteção a fauna.

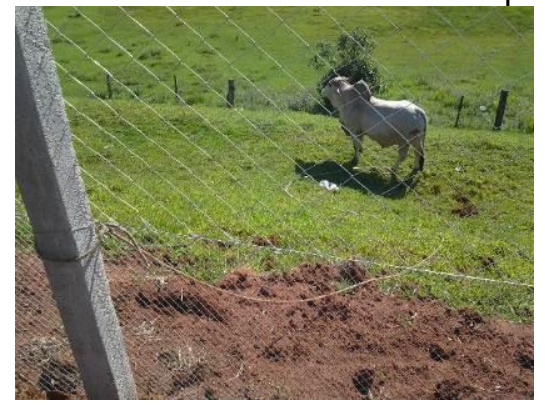

Foto 1: Animal amarrado indevidamente no mourão de concreto que compõem a estrutura da cerca guia de fauna (BR 386/RS, 04/12/2014).

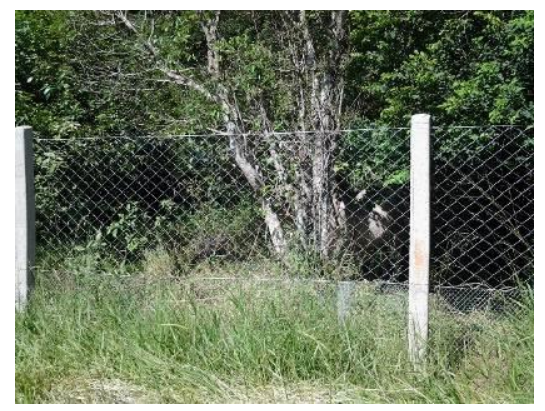

Foto 3: Animal amarrado indevidamente no mourão de concreto que compões a estrutura da cerca guia de fauna (BR 386/RS, 13/01/2015).

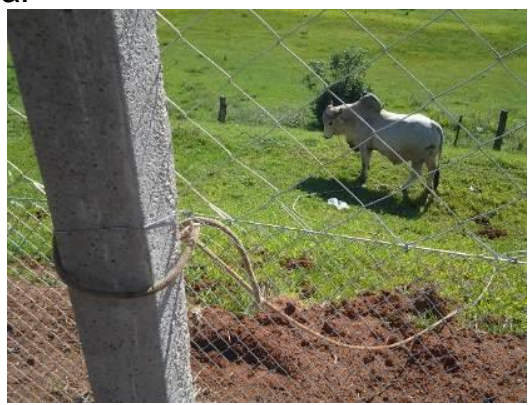

Foto 2: Detalhe da amarração indevida de animal no mourão de concreto que compões a estrutura da cerca guia de fauna (BR 386/RS, 04/12/2014).

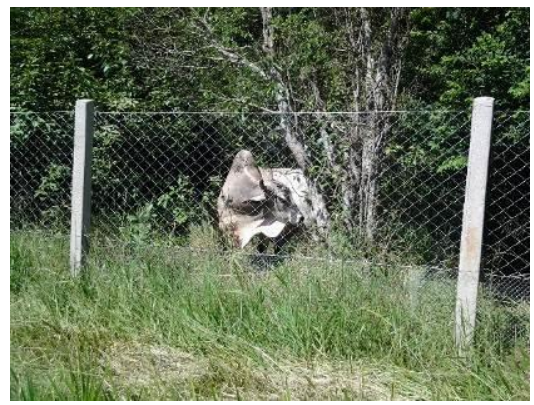

Foto 4: Detalhe do animal amarrado indevidamente no mourão de concreto que compões a estrutura da cerca guia de fauna (BR 386/RS, 13/01/2015).

Consequências das fotos 1 a 4: O projeto da cerca guia de fauna não prevê a solicitação extra gerado pelo esforço de tração criado pelo animal, desta forma os mourões de concreto 
se desprenderão do solo e consequentemente a cerca ficará solta podendo até mesmo cair. Assim a vida útil de projeto não será atendida gerando um desperdício de recursos da união, pois o serviço deverá ser refeito.

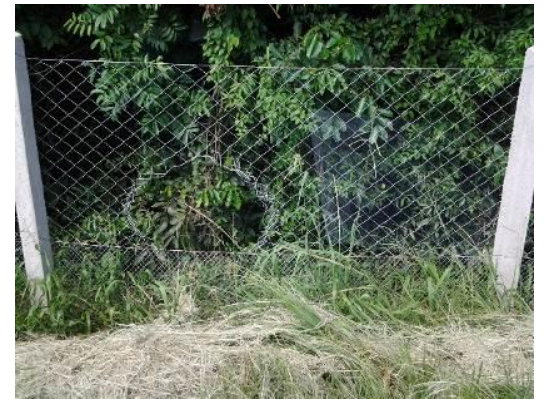

Foto 5: Dano gerado a tela que compõe a cerca guia de fauna, possivelmente por algum caçador, andarilho ou até mesmo colono da região (BR 386/ RS, 13/01/2015).

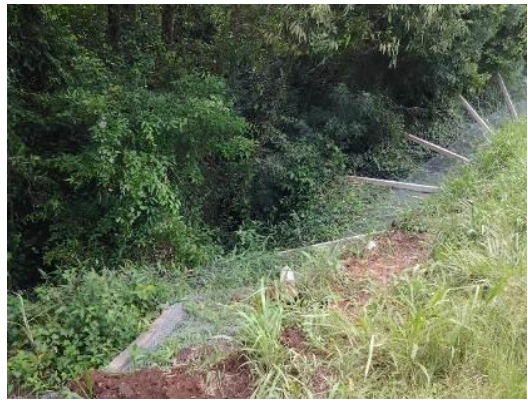

Foto 6: Cerca guia de fauna tombada por veículo (BR 386/ RS, 21/01/2015).

Consequências das fotos 5 e 6: Além do desperdício de recursos da união, pois o serviço deverá ser refeito, a finalidade principal da cerca guia de fauna não será atendida. Os animais terão livre acesso à rodovia aumentando os índices de mortalidade de fauna e consequentemente os danos ambientais.

Observações: a cerca possui a finalidade de gerar uma barreira que impeça ou dificulte o acesso dos animais à rodovia servindo como guia para os mesmos até uma passagem segura (passagem de fauna criada abaixo da rodovia), algum choque eventual pode ocorrer gerado pelo animal em corrida que não perceba a cerca a tempo (mas com esforço insuficiente para derrubada da cerca).

Aliada a conscientização da comunidade para a importância das estruturas de proteção a fauna e os cuidados necessários, os órgãos públicos devem prever estratégias de manutenção das mesmas, para com isso garantir a durabilidade mínima projetada. Nas imagens abaixo se evidencia a falta de manutenção que podem levar a redução da vida útil da estrutura. Dessa forma, ocorre uma desvalorização ou desperdício dos recursos público e consequentemente menor proteção à fauna futuramente.

Figura 6: Antes e depois, falta de manutenção a cerca de proteção a fauna.

\section{ANTES}

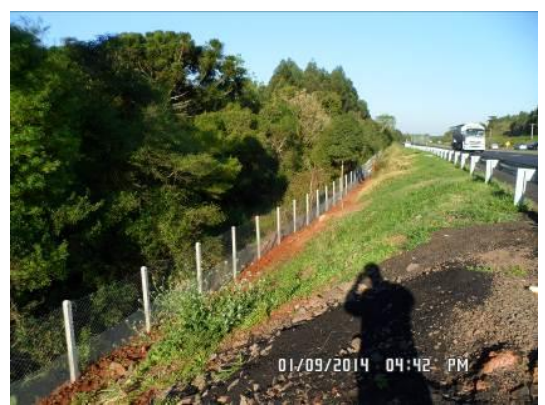

Foto 1: Cerca guia de fauna (BR 386/RS 01/09/2014).
DEPOIS

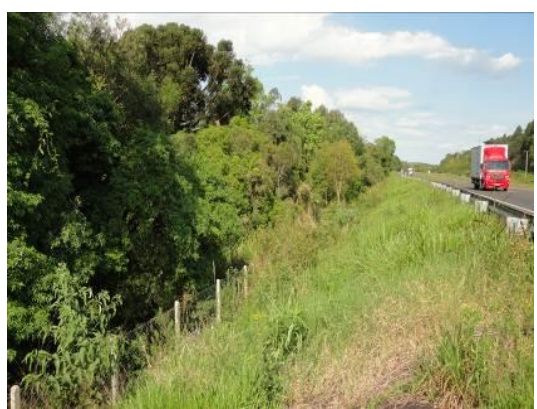

Foto 2: Cerca guia de fauna coberta pela vegetação (BR 386/RS, 04/12/2014). 


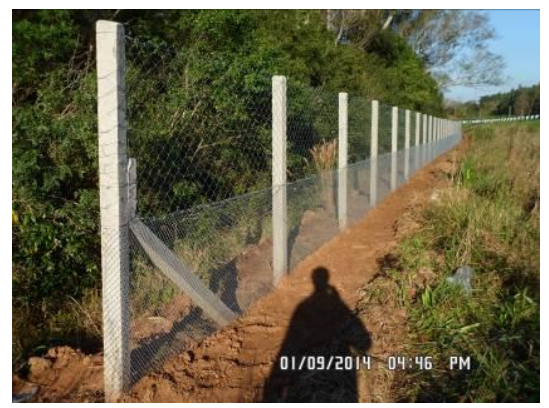

Foto 3: Cerca guia de fauna (BR $386 / \mathrm{RS}$, 01/09/2014).

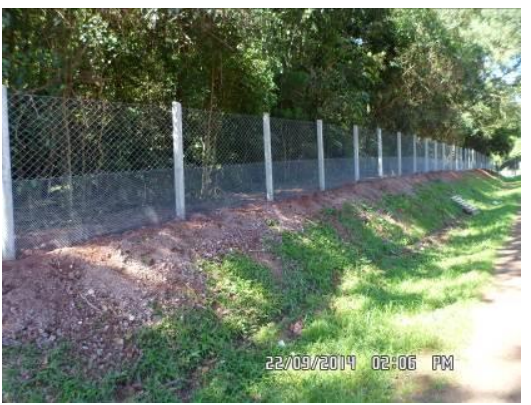

Foto 5: Cerca guia de fauna (BR 386/ RS, 22/09/2014).

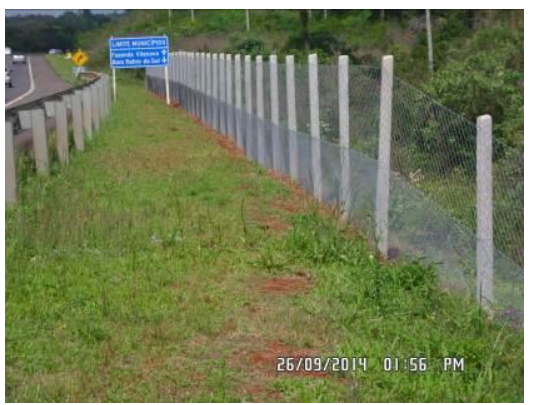

Foto7: Cerca guia de fauna (BR 386/ RS, 26/09/2014).

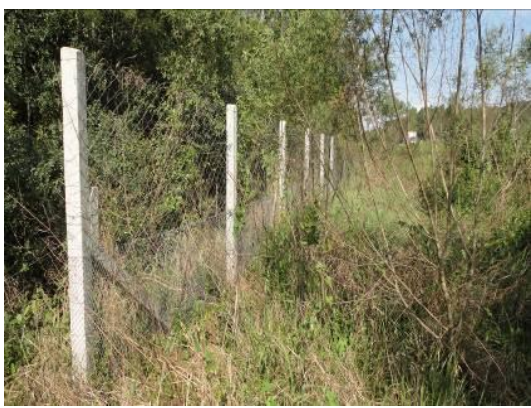

Foto 4: Detalhe da vegetação tomando a estrutura da cerca guia de fauna (BR 386/RS, 13/01/2015).

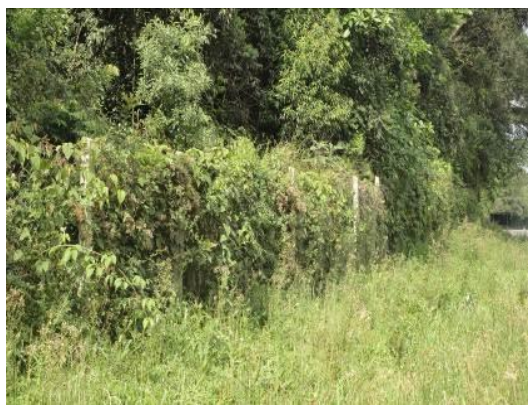

Foto 6: Cerca guia de fauna tomada pela vegetação (BR 386/ RS, 21/01/2015).

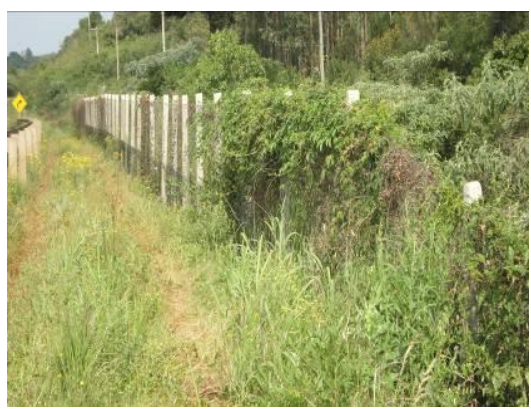

Foto 8: Vegetação se alastrando pela cerca guia de fauna (BR 386/ RS, 06/10/2015).

Consequências: fica evidente ao se comparar as fotos ímpares com as fotos pares que existe uma carência de manutenção periódica (roçadas e limpeza), especificamente para as cercas guia de fauna. Além do desperdício de recursos da união, pois em breve o serviço deverá ser refeito, a falta de manutenção acarretara a redução da vida útil de projeto das cercas. Desta forma, a finalidade principal da cerca guia de fauna não será atendida, pois, os animais terão livre acesso à rodovia e com isso aumentam os índices de mortalidade de fauna e consequentemente os danos ambientais.

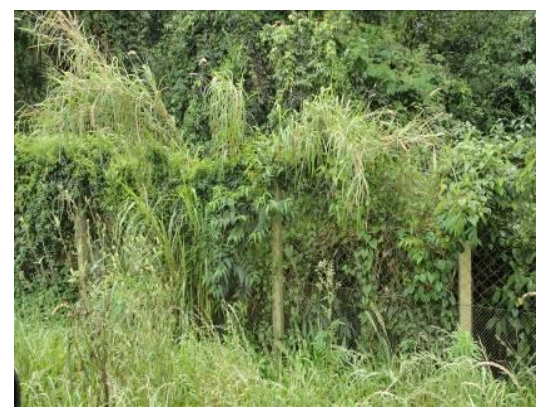

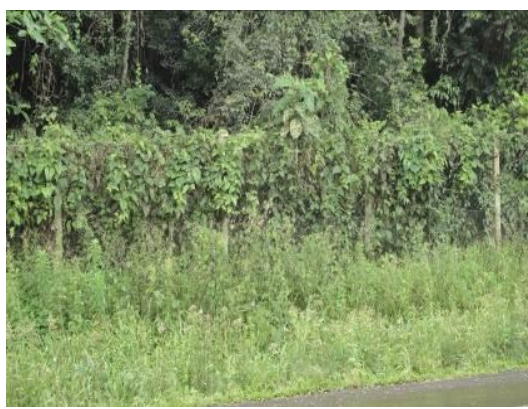

Foto 9: Vegetação sobre a cerca (BR 386/ Foto 10: Cerca quase impercebível (BR 386/ 
RS, 06/10/2015).

RS, 06/10/2015).

Observações fotos 9 e 10: a natureza possui poder regenerativo e conforme o passar o tempo a vegetação vai se intensificando entorno ou, até mesmo, sobre a cerca de fauna o que pode levar a ruptura da cerca. Isso ocorre porque, conforme a vegetação vai se alastrando/crescendo, o seu peso vai variando de forma a intensificar a solicitação sobre a tela da cerca. Essa solicitação é intensificada nos períodos chuvosos e com a ação do vento. Assim, caso não ocorra uma manutenção a estrutura não suportara e pode colapsar.

Não basta ter cuidado na execução qualificada dos serviços, se estes não forem mantidos de forma planejada. Sabe-se que o meio ambiente possui capacidade regenerativa e que os espaços ocupados pelo homem tendem a ser modificados conforme o passar do tempo. Sem a devida manutenção a natureza tenderá reocupar o seu espaço, e as estruturas criadas pelo homem tendem a ruína. Além disso, um investimento tão nobre, como a cerca guia e passagens de fauna, cujo apelo ambiental fica tão evidente não deveriam permanecer escondido sob a vegetação de forma a ficar no esquecimento depois de implantada. Portanto, o apelo visual das cercas guia de fauna colaboram para a chamada de atenção as questões de preservação da fauna e deveriam ficar a vista da sociedade.

\section{CONSIDERAÇÕES FINAIS}

As estruturas para transposição de obstáculos visam tanto prevenir a morte direta de indivíduos quanto restabelecer a conectividade de habitats, para isso existe uma diversidade de modelos de estruturas concebidas para atender uma espécie em particular, um grupo funcional ou toda comunidade local. Diversas outras medidas, tais como sinalização e instalação de dispositivos redutores de velocidade, tem sido adotadas, embora existam poucos dados objetivos quanto a sua eficácia.

Enquanto não existe consenso sobre a dimensão dos impactos causados pela mortalidade e fragmentação de habitats e seus reflexos, a instalação de estruturas visando facilitar o deslocamento transversal de fauna, frequentemente associada a dispositivos que evitem seu acesso a áreas de maior risco nas rodovias, tem sido a medida padrão adotada em grande parte dos países econômica e cientificamente desenvolvidos (LAUXEN, 2012).

Para implantação das medidas de proteção a fauna, os órgãos federais e a sociedade em geral deve se cercar de diversas fontes para tomada de decisão. Os Estudos de Impacto Ambiental e Planos Básicos Ambientais 
aliados aos projetos básicos de engenharia produzem os subsídios necessários para a indicação da quantidade, tipologia e a localização apropriada para instalação dos dispositivos de travessia de fauna. Além disso, na fase de obra, estes documentos são compatibilizados com os projetos de engenharia e aprovados pelos órgãos ambientais licenciadores (BRASIL, 2012).

Informações como a distribuição natural, grau de ameaça, distribuição e área de vida das espécies nativas brasileiras, são essenciais para a definição dos programas de mitigação. Estas informações deveriam ser reunidas em um banco de dados nacional de fácil acesso. Desta forma, com o acesso facilitado a um rico banco de informações pode-se reduzir a margem de erro na fase de definições além de reduzir os prazos para elaboração de projetos. Visto que, o período de coleta de dados é demorado e a distribuição geográfica de um empreendimento particular em licenciamento é variada.

A manutenção das estruturas de proteção à fauna é de suma importância tanto para a preservação dos animais e consequentemente redução dos índices de acidentes envolvendo condutores e a fauna, como o respeito pelo dinheiro público. Importante que os órgãos Federais, Estaduais e Municipais incluam em seu escopo de serviços de manutenção de rodovias as cercas guia de fauna. Desta forma, além de garantir a vida útil de projeto, a visão das estruturas aliada a campanhas de conscientização tende a fazer com que a sociedade assimile a importância destas e colabore para a sua conservação.

Para a realização de empreendimentos rodoviários, os princípios de viabilidade ambiental do sistema de transportes, o respeito à necessidade de preservação do meio ambiente e o desenvolvimento sustentável devem ser observados. Sendo assim, almeja-se que os projetos do setor de transportes incluam diagnósticos, prognósticos, ações concretas e monitoramentos, para que o desenvolvimento que as rodovias proporcionam ao país ocorra de forma equilibrada e coerente com os princípios da sustentabilidade (PIMENTA, et al, 2014). 


\section{REFERÊNCIAS}

BERNUCCI, L. B., MOTTA, L. M. G., CERATTI, J. A. P., SOARES, J. B. Pavimentação asfáltica: formação básica para engenheiros. Liedi Bariani Bernucci, et al. Rio de Janeiro: PETROBRAS: ABEDA, 2006.

BRASIL. Portaria no 289, de 16 de julho de 2013b. Dispõe sobre procedimentos a serem aplicados pelo Instituto Brasileiro do Meio Ambiente e dos Recursos Naturais Renováveis - IBAMA no licenciamento ambiental de rodovias e na regularização ambiental de rodovias federais. Diário Oficial da União, Brasília, DF, 19 de jul. 2013. Disponível em: http://www.ibama.gov.br/sophia/cnia/legislacao/MMA/PT0289-160713.pdf. Acesso em: 04 setembro. 2015. Brasília, 2013b.

BRASIL. Constituição da República Federativa do Brasil de 1988. Diário Oficial da União, Brasília, DF, 05 de out. 1988. Disponível em: http://www.planalto.gov.br/ccivil 03/constituicao/constituicao.htm. Acesso em: 04 setembro. 2015. Brasília, 1988b.

BRASIL. Monitoramento e Mitigação de Atropelamentos de Fauna. Coleção estrada verde, volume 1/3. Brasília, 2012.

CALTRANS. Wildlife crossings guidance manual, version 1.1. Available online at: http://www.dot.ca.gov/hq/env/bio/wildlife crossings/. Acessed: 25 de setembro de 2015. California: EUA, 2009.

CONAMA. Resolução no 237, de 19 de dezembro de 1997. Dispõe sobre a revisão e complementação dos procedimentos e critérios utilizados para o licenciamento ambiental. Diário Oficial da União, Brasília, DF, 22 dez. 1997. Disponível em: http://www.mma.gov.br/port/conama/processos/61AA3835/LivroConama.pdf.

Acesso em: 11 de setembro. 2015. Brasília, 1997a.

FORMAN, R. T. T. \& ALEXANDER, L. E. Roads and their major ecological effects. Annual Review of Ecology and Systematics 29: 207-231. 1998.

GOLDSTEIN, P. Z.; DESALLE, R.; AMATO, G.; VOGLER, A. Conservation genetics at the species boundary. Conservation Biology, n.14, p.120-131, 2000.

GOOSEM, M. Internal fragmentation: the effects of roads, highways, and powerline clearings on movements and mortality of rainforest vertebrates. In: LAURANCE, W.F. \& BIERREGARD, R.O.JR. (Eds.). Tropical forest remnants: ecology, management, and conservation of fragmented communities. Chicago: University of Chicago Press, 1997.

GRUPO ECO. Implantação de passagem de fauna. Disponível em: http://www.grupoecoeco.com.br/passagem-de-fauna/. Acesso em: 18 setembro. 2015. 
IBAMA. Instrução Normativa $n^{\circ}$ 184, de 17 de julho 2008. Estabelece, no âmbito desta Autarquia, os procedimentos para o licenciamento ambiental federal. Diário Oficial da União, Brasília, DF, 18 de jul. 2008. Disponível em: http://6ccr.pgr.mpf.mp.br/legislacao/legislacao-docs/instrucoesnormativas/IN 184 2008.pdf. Acesso em: 11 setembro. 2015. Brasília, 2008.

IUELL, B., G. J. BEKKER, R. CUPERUS, J. DUFEK, G. FRY, C. HICKS, V. HLAVÁC, V. B. KELLER, C. ROSELL, T. SANGWINE, N. TORSLOV \& B. L. M. WANDALL. Wildlife and traffic: A European handbook for identifying conflicts and designing solutions. Brussels, European Co-operation in the field of Scientific and Technical Research. 2003.

LAUXEN, M. S. A mitigação dos impactos de rodovias sobre a fauna: um guia de procedimentos para tomada de decisão. Trabalho de conclusão de curso de pós-graduação em Diversidade e Conservação de Fauna junto ao Programa de Pós-Graduação em Biologia Animal/Instituto de Biociências - UFRS. 2012.

LYREN, L. M. Movement patterns of coyotes and bobcats relative to roads and underpasses in the Chino Hills area of southern California. Thesis (Philosophers Doctor) presented to the California State Polytechnic University, Pomona, USA. 2001.

PESSOA JÚNIOR, E. Manual de obras rodoviárias e pavimentação urbana: execução e fiscalização. São Paulo: Pini, 2014.

PIMENTA, A. F. F., RATTON, E., BLASI, G. F., SOBANSKI, M. B., ALBACH, D. M. Gestão para o licenciamento ambiental de obras rodoviárias: conceitos e procedimentos. Aline Figueiredo Freitas Pimenta, et al. - Curitiba: UFPR/ITTI, 2014.

PRADA, C. S. Atropelamento de vertebrados silvestres em uma região fragmentada do nordeste do estado de São Paulo: quantificação do impacto e análise de fatores envolvidos. Universidade Federal de São Carlos. Mestrado. São Carlos, 2004.

ROMANINI, P. H. Rodovias e meio ambiente: principais impactos ambientais, incorporação da variável ambiental em projetos rodoviários e sistema de gestão ambiental. Tese de Doutorado. Universidade de São Paulo, São Paulo, 2000.

SCHONEWALD-COX, C. M.; BUECHNER, M. Park protection and public roads. In Conservation Biology: The Theory and Practice of Nature Conservation, Preservation and Management (FIEDLER, P. L.; JAIN, S. eds), Chapman and Hall, New York, 1992, p. 373-396. 
VALEC. Norma Geral Ambiental: passagens inferiores de fauna. NGL-5.03.0116.015. SUAMB: DIPLAN, 2001.

Recebido:17/11/2015

Aprovado:05/12/2015 